Corrigendum

\title{
Corrigendum to "IQP-VV-102, a Novel Proprietary Composition for Weight Reduction: A Double-Blind Randomized Clinical Trial for Evaluation of Efficacy and Safety"
}

\author{
Barbara Grube, ${ }^{1}$ Udo Bongartz, ${ }^{2}$ and Felix $\mathrm{Alt}^{3}$ \\ ${ }^{1}$ Practice for General Medicine, Kurfürstendamm 157/158, 10709 Berlin, Germany \\ ${ }^{2}$ Analyze \& Realize GmbH, Weißenseer Weg 111, 10369 Berlin, Germany \\ ${ }^{3}$ Analyze \& Realize GmbH, Waldseeweg 6, 13467 Berlin, Germany \\ Correspondence should be addressed to Felix Alt; falt@a-r.com \\ Received 18 October 2016; Accepted 16 November 2016
}

Copyright (C) 2016 Barbara Grube et al. This is an open access article distributed under the Creative Commons Attribution License, which permits unrestricted use, distribution, and reproduction in any medium, provided the original work is properly cited.

In the article titled "IQP-VV-102, a Novel Proprietary Composition for Weight Reduction: A Double-Blind Randomized Clinical Trial for Evaluation of Efficacy and Safety" [1], there was an error under Section 3.1.3: Hip Circumference, which should be corrected as follows.

3.1.3. Hip Circumference. The mean hip circumference in the IQP-VV-102 group at baseline (V2) was $108.1 \mathrm{~cm}$ (SD 6.7) while the placebo group was $106.5 \mathrm{~cm}(\mathrm{SD} 6.5)(p=0.101)$.

In addition, the declaration statement in the Conflict of Interests section "The authors declare that there is no conflict of interests regarding the publication of this paper" should be replaced with the following declaration "InQpharm Europe Ltd. is the manufacturer of the investigational product and oversaw the trial and manuscript preparation as the sponsor."

\section{References}

[1] B. Grube, U. Bongartz, and F. Alt, "IQP-VV-102, a novel proprietary composition for weight reduction: a double-blind randomized clinical trial for evaluation of efficacy and safety," Evidence-Based Complementary and Alternative Medicine, vol. 2015, Article ID 413075, 7 pages, 2015. 


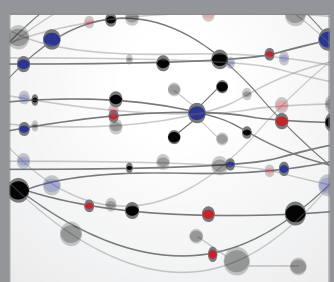

The Scientific World Journal
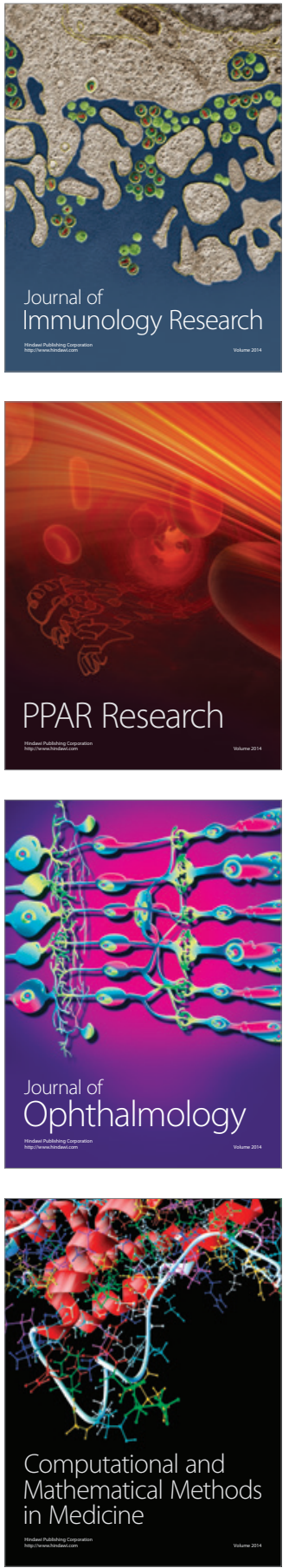

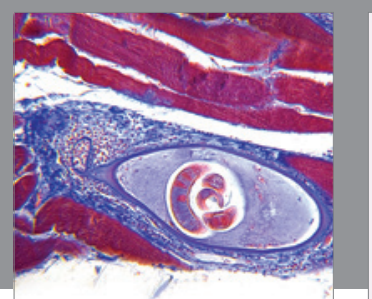

Gastroenterology Research and Practice

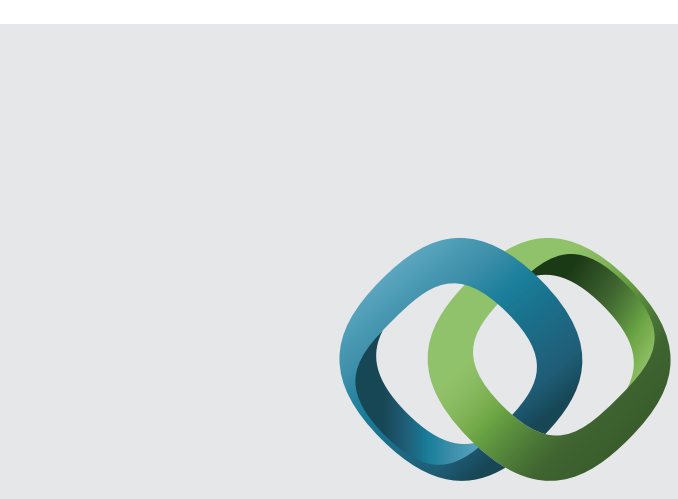

\section{Hindawi}

Submit your manuscripts at

http://www.hindawi.com
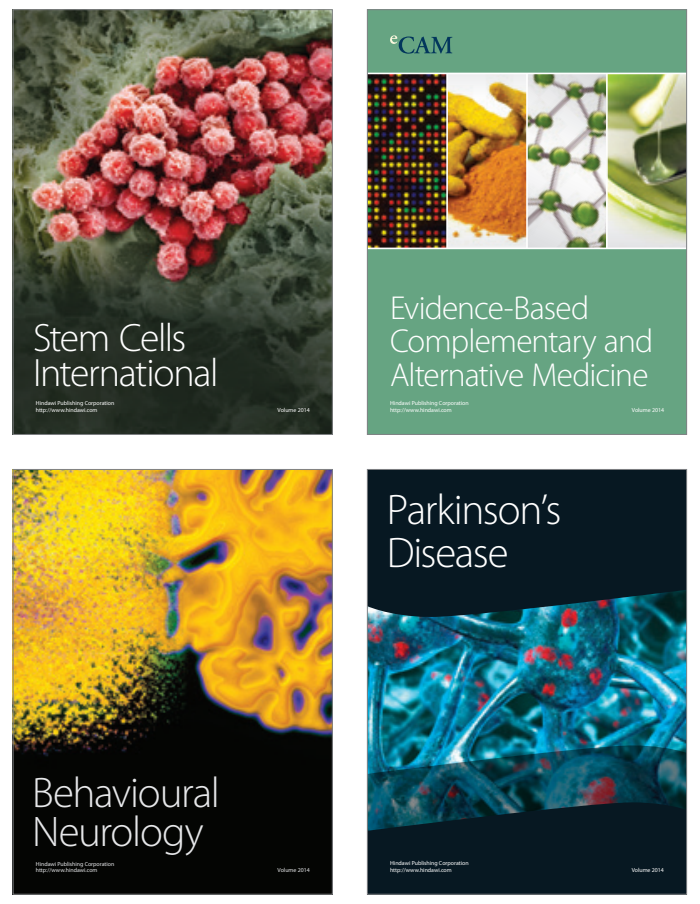
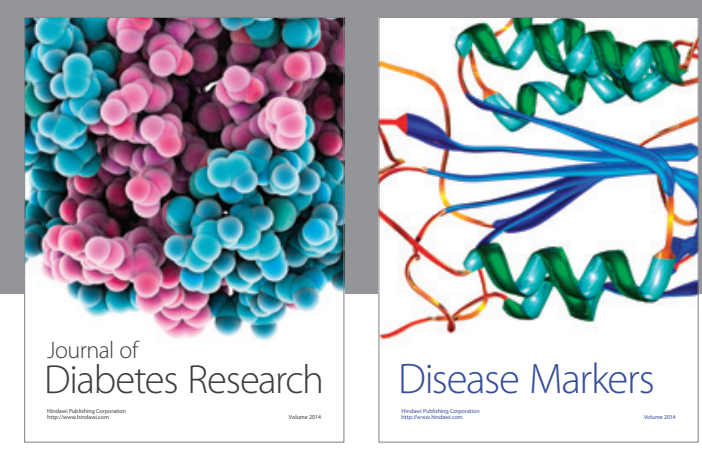

Disease Markers
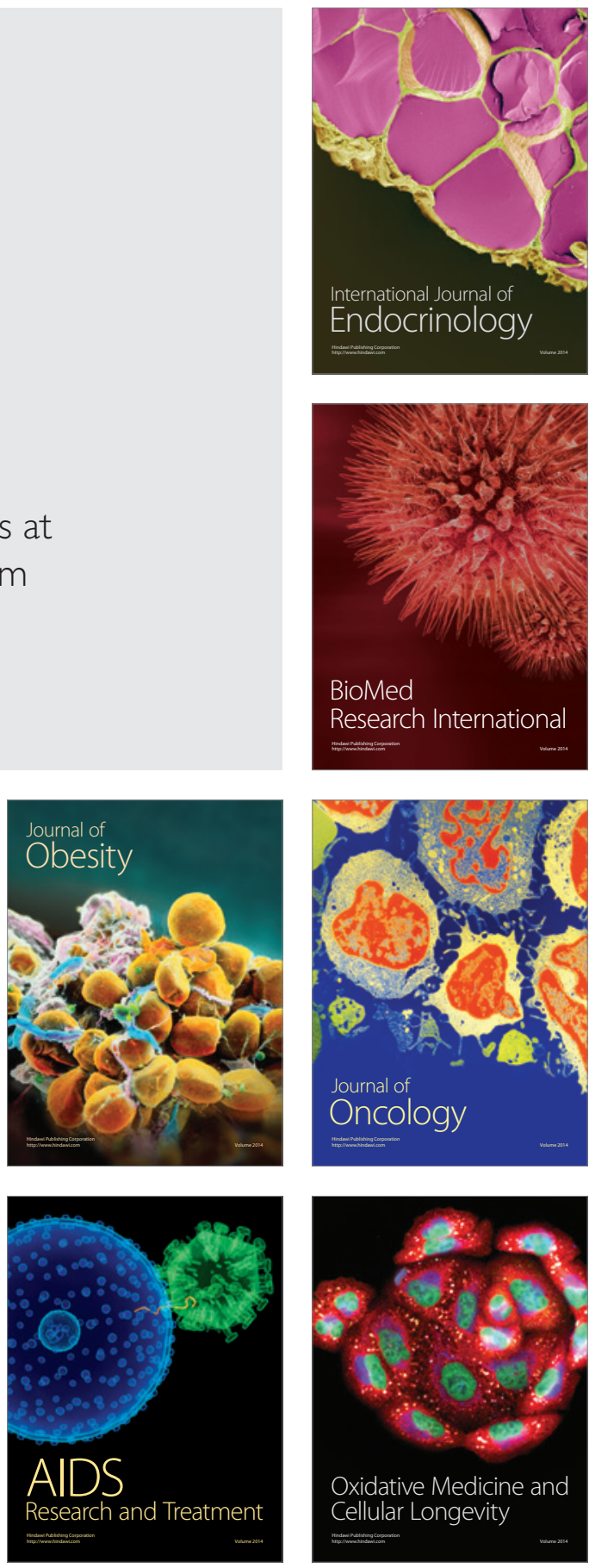